\title{
Amiodarone-induced thyrotoxicosis with paroxysmal supraventricular (ectopic atrial) tachycardia: case report and review of the literature
}

\author{
Zofia Kolesińska ${ }^{1 \sharp}$, Katarzyna Siuda"\#\#, Waldemar Bobkowski², Marek Niedziela ${ }^{1}$
}

\begin{abstract}
1Department of Pediatric Endocrinology and Rheumatology, $2^{\text {nd }}$ Chair of Pediatrics, Poznan University of Medical Sciences, Poznan, \#Students Circle of Pediatric Endocrinology and Rheumatology, \#\#Student Pediatrics Society, Poland

2Department of Pediatric Cardiology and Nephrology, $1^{\text {st }}$ Chair of Pediatrics, Poznan University of Medical Sciences, Poznan, Poland
\end{abstract}

Submitted: 20 May 2011

Accepted: 30 August 2011

Arch Med Sci 2013; 9, 2: 372-376

DOI: $10.5114 /$ aoms.2012.32790

Copyright @ 2013 Termedia \& Banach

The most common side effects of amiodarone therapy include disruptions of thyroid function with the incidence range from 14-18\% [1, 2]. In fact this antiarrhythmic drug is rich in iodine and during common therapy the oversupply of iodine is 50-100 times higher than its optimal intake. Moreover, due to its intrinsic qualities (not related to iodine load), such as structural resemblance to thyroid hormones, the ability of inhibiting deiodinase enzymes or tissue toxicity, amiodarone can alter thyroid balance via different mechanisms [1, 2]. Impaired functioning of the thyroid has various forms: from subclinical changes in hormone concentrations, to overt clinical problems: amiodarone-induced thyrotoxicosis (AIT) and amiodarone-induced hypothyroidism $(\mathrm{AlH})$. In areas rich in iodine, $\mathrm{AlH}$ is often observed, whereas in areas of low iodine supply, AIT is often observed. Amiodarone-induced thyrotoxicosis occurs in men more frequently, while $\mathrm{AlH}$ is more common in women. In contrast to the more easily treatable hypothyroidism, AIT poses a challenge for clinicians. Amiodarone-induced thyrotoxicosis can present as AIT I, AIT II or as a mixed type [1, 2]. They differ from each other in the pathogenesis, laboratory test results, ultrasound image and iodine uptake observed. The necessity to indicate the type of AIT is important in order to provide the appropriate prompt treatment of the patient. Amiodarone-induced thyrotoxicosis I usually develops in abnormal thyroid glands (mainly multinodular goiter or in preexisting Graves' disease) where an oversupply of iodine due to the amiodarone therapy is responsible for the overproduction of thyroid hormones. Amiodarone-induced thyrotoxicosis I usually shows high radioactive iodine uptake and increased blood flow on ultrasonography. The presence of thyroid stimulating receptor antibodies (TRAb) in the patient's serum might be indicative. In contrast, AIT II presents as a destructive drug-induced thyroiditis with low radioactive iodine uptake and normal blood flow [1, 2]. Some inflammation markers as C-reactive protein (CRP) or interleukin-6 (IL-6) might be helpful in the diagnostic process. Some authors underline the beneficial role of Tc-99m sestamibi scintigraphy in AIT type differentiation. Nevertheless, the most reliable tests are iodine-uptake and colorflow Doppler sonography (CFDS) [6, 7]. In the case of AIT I, first line treat-

\author{
Corresponding author: \\ Assoc. Prof. Marek Niedziela \\ MD, PhD \\ Department of Pediatric \\ Endocrinology \\ and Rheumatology \\ Poznan University \\ of Medical Sciences \\ 27/33 Szpitalna St \\ 60-572 Poznan, Poland \\ Phone: +48 618491481 \\ Fax: +48 618480291 \\ E-mail: mniedzie@ump.edu.pl
}


Table I. Characteristics of AIT types $[5,6]$

\begin{tabular}{|lll|}
\hline Parameter & AIT 1 & AIT 2 \\
\hline Pre-existing thyroid disorder & Yes & No \\
\hline IL-6 and CRP concentrations* & Normal & Increased \\
\hline TRAb presence & Positive & Negative \\
\hline Ultrasound image & Goiter or multinodular goiter & Normal or small and hypoechogenic gland \\
\hline CFDS $^{* * *}$ & Increased & Normal \\
\hline lodine uptake $^{* * *}$ & Low, normal or increased & Very low, no uptake \\
\hline MIBI $^{* * *}$ & Increased uptake & Decreased, no uptake \\
\hline Pathogenesis & $\begin{array}{l}\text { Oversupply of iodine leads to } \\
\text { overproduction of thyroid hormones } \\
\text { (Jod-Basedow effect) }\end{array}$ & Destructive drug-induced thyrotoxicosis \\
\hline
\end{tabular}

*The usefulness of its predictive role is questionable as these markers of inflammation are not specific [5, 7]. ${ }^{* *}$ TRAb are the most reliable antibodies in the differentiation process; if present one should consider predominately AIT type I [2, 5]. ${ }^{* * *}$ These methods are currently the most reliable tools used to distinguish between the AIT types [5, 7, 8]. ${ }^{* * * \star}$ A promising novel method of AlT type diagnosis that still needs further studies [7, 8]

ment involves thionamides in combination with potassium perchlorate, and in AIT II treatment includes glucocorticoids [1, 2]. Table I presents the characteristics that differentiate and help distinguish between the types of AIT.

A 16-year-old girl was referred to the Department of Pediatric Endocrinology by the cardiologist one month after she began experiencing symptoms of hyperthyroidism. The patient had a type II ASD surgical correction 12 months prior to referral (Figure 1). Post-operatively she developed paroxysmal supraventricular (ectopic atrial) tachycardia (Figure 2) and was prescribed amiodarone intravenously, followed by a $100 \mathrm{mg}$ dose orally, two times daily for 6 months.

Seven months after cessation of therapy, the patient developed symptoms of hyperthyroidism (weight loss, emotional lability, heat intolerance). Laboratory tests confirmed AIT: TSH $0.006 \mu \mathrm{IU} / \mathrm{ml}$ $\downarrow$ (norm. 0.27-4.20), fT3 $13.81 \mathrm{pg} / \mathrm{ml} \uparrow$ (norm. 2.04.4) and fT4 $4.96 \mathrm{ng} / \mathrm{ml} \uparrow$ (norm. 0.93-1.70), a negative titer of antithyroid antibodies [anti-thyroperoxidase antibodies (anti-TPO) $8.13 \mathrm{IU} / \mathrm{ml}$ (norm. 0-34) and anti-thyroglobulin antibodies (anti-TG) $11.11 \mathrm{lU} / \mathrm{ml}$ (norm. 0-115)]. Thyroid ultrasound was normal. However, thyroid scintigram using Tc-99m activity of $150 \mathrm{MBq}$ showed almost an absence of tracer in the thyroid parenchyma. The patient was started on ATD (thiamazole) $10 \mathrm{mg}$ three times daily and $\beta$-blocker (bisoprolol) $2.5 \mathrm{mg}$ once daily.

After 1 month the patient was admitted for diagnostics. The patient's family history of thyroid disease is unremarkable and she presented with good general health (body weight: $46.9 \mathrm{~kg}$, height: 166.1 $\mathrm{cm})$. Physical examination revealed: heart rate of 95 beats/min, increased skin temperature and a slight tremor of the upper limbs. Thyroid was visible and palpable in a normal setting of the head (goiter grade II, based on WHO classification) with no ophthalmic abnormalities. Laboratory studies revealed: TSH 0.013 ulU/I $\downarrow$ (norm. 0.470-0.640), fT3 $5.6 \mathrm{pg} / \mathrm{ml} \uparrow$ (norm. 1.45-3.48) and fT4 2.38 $\mathrm{ng} / \mathrm{ml} \uparrow$ (norm. 0.71-1.85). All thyroid antibodies were negative [anti-TPO $0.0 \mathrm{U} / \mathrm{ml}$ (norm. <60), antiTG $30.0 \mathrm{U} / \mathrm{ml}$ (norm. < 60) and TRAb < $0.3 \mathrm{U} / \mathrm{l}$ (norm. < 1.5)]. Ultrasound showed slight enlargement and hypoechogenicity (right lobe $1.7 \mathrm{~cm}$ width $\times 1.4 \mathrm{~cm}$ depth, left lobe 1.3 width $\times 1.5 \mathrm{~cm}$ depth; isthmus $0.3 \mathrm{~cm}$ depth). Color-flow Doppler sonography showed slightly increased intra-thyroidal blood flow especially in the left lobe (Figures $3 \mathrm{~A}$, B). The patient's good response to treatment with ATD, increased vascular flow and absence of inflammation (CRP: $0.36 \mathrm{mg} / \mathrm{dl}$ ) supported AIT type I. However, scanty technetium uptake typical for AIT type II was also evident, so therefore a mixed form of AIT should be postulated.

The patient was continued on ATD (thiamazole 3 times daily $10 \mathrm{mg}$ ) and was given propranolol (10 mg) two times daily. At the first follow-up appointment, the propranolol was discontinued as the tachycardia had subsided. All laboratory results and treatment methods are summarized in Table II.

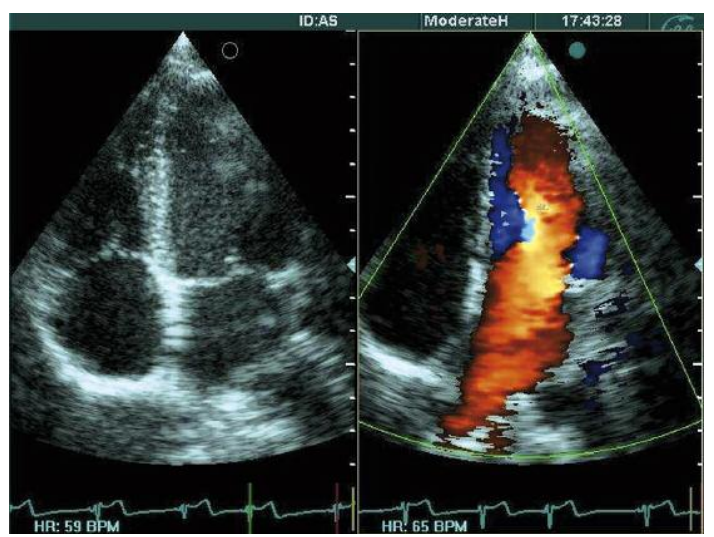

Figure 1. Echocardiogram in apical four-chamber view of successful surgical closure of secundum atrial septal defect 


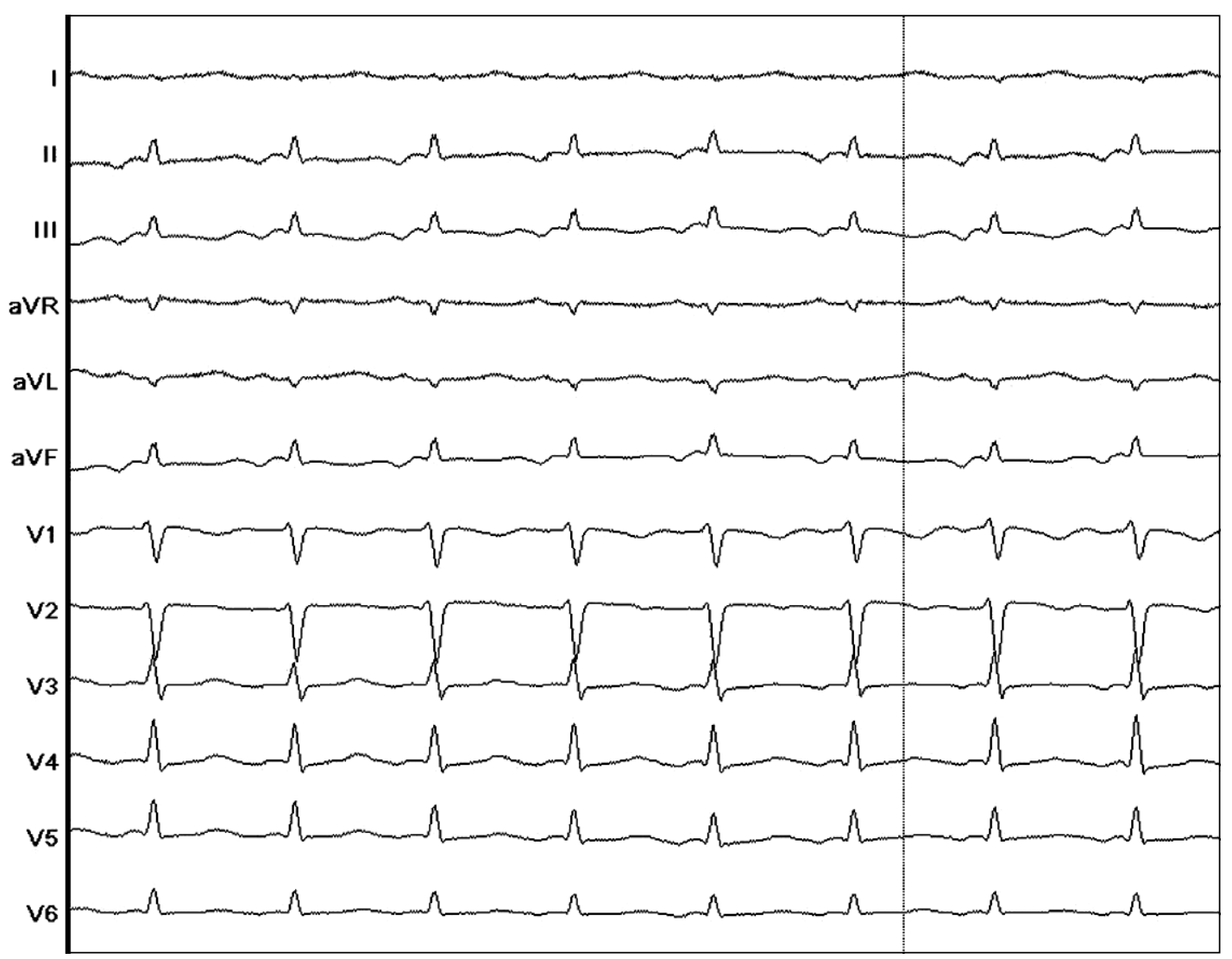

Figure 2. Twelve-lead electrocardiogram $(50 \mathrm{~mm} / \mathrm{s})$ showing ectopic atrial tachycardia with cycle length $380 \mathrm{~ms}$ $(157 / \mathrm{min})$

Five months after diagnosis, during combination therapy (thionamide $+\mathrm{L}-\mathrm{T} 4$ ), in order to prevent iatrogenic hypothyroidism, a normal thyroid image was observed. This contrasts with the image from an examination during the $7^{\text {th }}$ month of treatment (Figures 4 A, B) where a heterogeneous thyroid gland with small, yet multiple hypoechogenic areas with increased blood flow (power and color Doppler) was observed - typical of an autoimmune process. Finally, 4 weeks later, ultrasound once again returned to normal.

We present a patient with paroxysmal supraventricular (ectopic atrial) tachycardia treated suc- cessfully with amiodarone. However, treatment later resulted in AIT. The treatment chosen for our patient's AIT was that typical for AIT I. However, some features also gave rise to her diagnosis of partial AIT II. Perchlorate and glucocorticoids with their toxic effects were avoided.

The simultaneous supply of thionamides and thyroid hormone supplementation is effective and prevents adverse fluctuations that can otherwise be observed in thyroid hormone levels [9]. Now the question arises: how long should we treat pediatric patients with ATD before radical treatment measures need to be considered? The time from
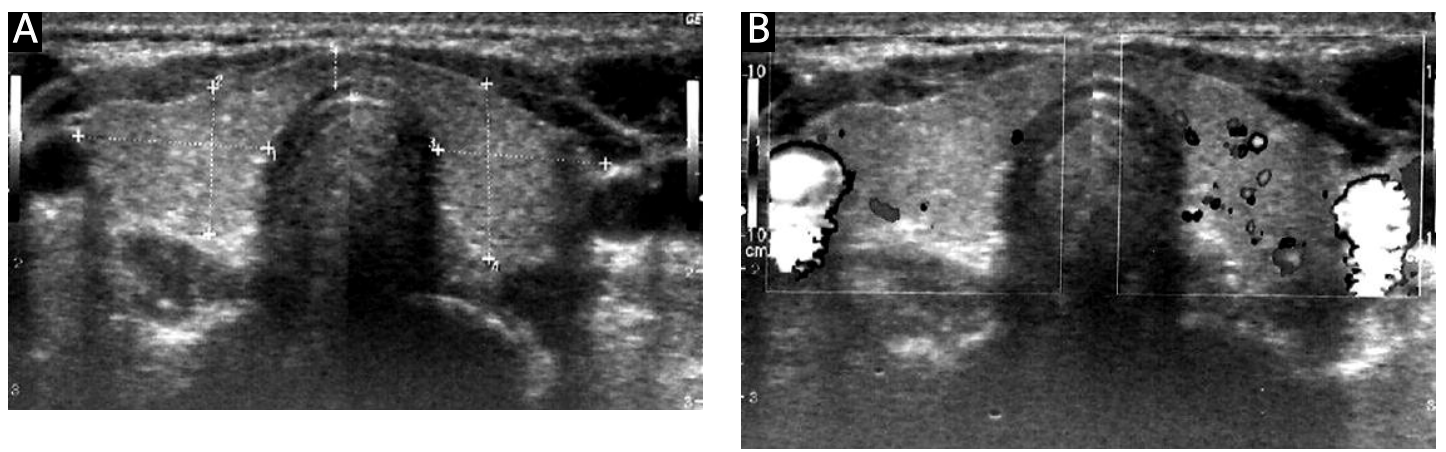

Figure 3. Thyroid ultrasound 4 weeks after initiation of treatment with ATD: A - In gray scale - uniformly slightly reduced echogenicity of both lobes. B - CFDS - a slight intensification of vascular flow especially in the left lobe 
Table II. Laboratory tests in a patient with amiodarone-induced hyperthyroidism (abnormal values are given in bold)

\begin{tabular}{|c|c|c|c|c|c|c|c|c|}
\hline $\begin{array}{l}\text { Time of } \\
\text { the therapy }\end{array}$ & $\begin{array}{c}\text { MMI } \\
{[\mathrm{mg} / \text { day] }}\end{array}$ & $\begin{array}{c}\mathrm{L}-\mathrm{T} 4 \\
{[\mu \mathrm{g} / \text { day }]}\end{array}$ & $\begin{array}{c}\text { fT4 } \\
0.71-1.85 \\
\text { ng/dl }\end{array}$ & $\begin{array}{c}\mathrm{fT} 3 \\
1.45-3.48 \\
\mathrm{pg} / \mathrm{ml}\end{array}$ & $\begin{array}{c}\text { TSH } \\
0.470-4.640 \\
\mathrm{mlU} / \mathrm{l}\end{array}$ & $\begin{array}{c}\text { anti-TPO } \\
<60 \\
\mathrm{U} / \mathrm{ml}\end{array}$ & $\begin{array}{c}\text { anti-TG } \\
<60 \\
\mathrm{U} / \mathrm{ml}\end{array}$ & $\begin{array}{l}\text { TRAb } \\
<1.0 \\
U / 1\end{array}$ \\
\hline \multirow[t]{2}{*}{ At diagnosis } & & & $4.96 \uparrow$ & $13.81 \uparrow$ & $0.006 \downarrow$ & 8.13 & 11.11 & - \\
\hline & 30 & & $(0.93-1.7)$ & $(2.0-4.4)$ & $(0.27-4.2)$ & $(0-34)$ & $(0-115)$ & \\
\hline 4 weeks later* & 30 & & $2.38 \uparrow$ & $5.60 \uparrow$ & $0.013 \downarrow$ & 0.0 & 30.0 & $<0.3$ \\
\hline 5 weeks later & 30 & & 1.43 & $3.68 \uparrow$ & $0.015 \downarrow$ & & & \\
\hline 2 months & 20 & & 0.978 & 2.72 & $0.009 \downarrow$ & & & \\
\hline 2 months 3 weeks & 10 & & 0.841 & 2.31 & $9.49 \uparrow$ & & & \\
\hline 3 months 2 weeks & 10 & & $0.663 \downarrow$ & 2.40 & $20.4 \uparrow$ & & & \\
\hline 3 months 3 weeks & 5 & 50 & & & & & & \\
\hline 5 months & 5 & 75 & 1.35 & 3.11 & 0.703 & & & \\
\hline 7 months 2 weeks ${ }^{\star *}$ & ** 5 & 75 & 1.15 & 2.57 & 3.150 & & & \\
\hline 8 months 2 weeks & 2.5 & 75 & 1.09 & 1.97 & 1.906 & 34 & 25 & $<0.3$ \\
\hline
\end{tabular}

*Thyroid ultrasound examination 4 weeks after diagnosis (Figures 1 A, B). **Thyroid ultrasound examination 7 months later (Figures 2 A, B)
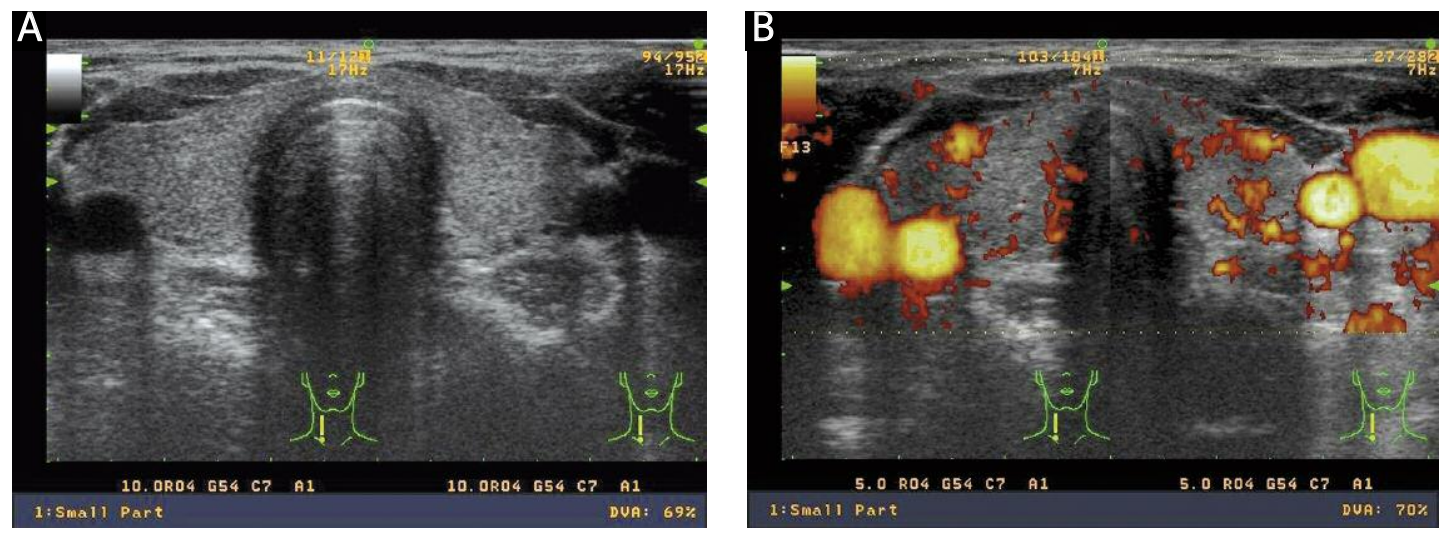

Figure 4. Thyroid ultrasound 7 months after diagnosis, during combination therapy (thionamide + L-thyroxine). A - In gray scale - mildly decreased echogenicity of both lobes. B - PFDS - increased vascular flow

the beginning of amiodarone treatment to the possible emergence of thyrotoxicosis lasts about 3 years [2]. Additionally, due to the long half-life of the drug (which varies among authors, from around 40 to 100 days, and is even longer for its main metabolite desethylamiodarone), its accumulation in the body, slow release from the tissues and iodine overload, thyrotoxicosis symptoms might even be observed several months after cessation of therapy [1, 2]. Thus, it appears that the time required for treatment and follow-up monitoring may extend even to 2 years after amiodarone discontinuation, in order to ensure that the proper hormonal balance is restored. It is then also imperative to wait with the withdrawal of ATD several weeks after euthyroidism is restored, because even then we can expect some fluctuations in hormone levels, as in this case report.

This poses another question: how to further treat AIT in pediatrics if after this time period there is no improvement? To date, choices have been based on the radioactive iodine uptake of the thyroid gland. If the uptake was minimal then thyroidectomy was the only recommendation. Currently, there are new reports in the literature demonstrating the efficacy of radioiodine therapy, despite low or minimal iodine uptake $[3,4]$. Therefore, if confirmed by studies, treatment should begin with radioiodine therapy, thus avoiding all the possible difficulties and complications associated with surgical procedures in children.

One more issue remains to be considered, namely when the discontinuation of amiodarone treatment is not possible, is 131-I still the most appropriate treatment method? Or does surgery then remain the only option? Can the approach proposed in adults [5] be applied in pediatric patients?

In conclusion, abnormalities of the thyroid gland can be observed even several months after cessation of amiodarone treatment. It is therefore imper- 


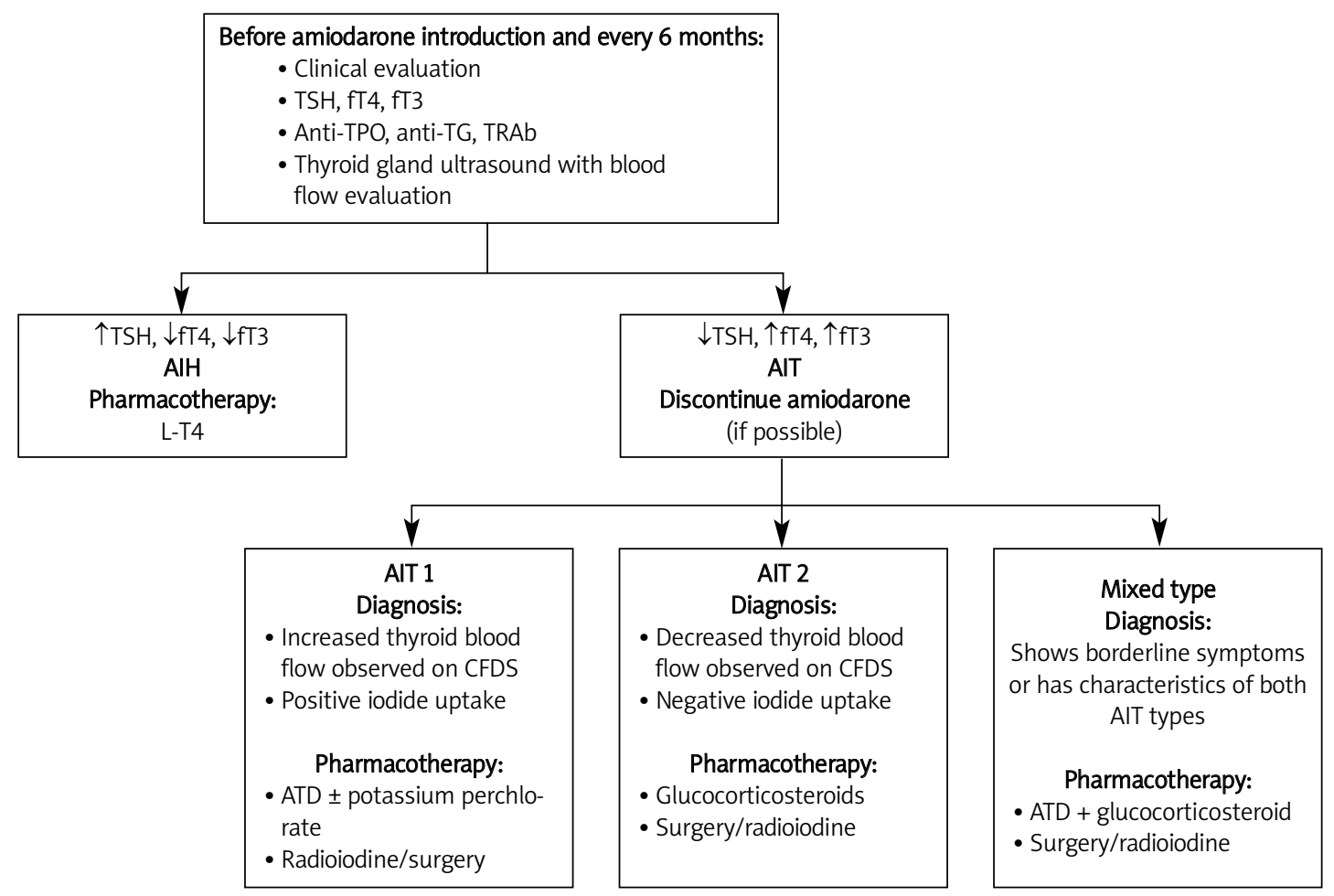

Figure 5. Diagnostic flowchart for evaluating patients with amiodarone-induced thyroid disturbances [5, 6]

ative to monitor the patient's thyroid function before, during and for several years after treatment with this drug. A diagnostic flowchart for evaluating patients with amiodarone-induced thyroid disturbances is presented in Figure 5 and provides a good summary.

\section{Acknowledgments}

The authors' (Zofia Kolesińska and Katarzyna Siuda) contributions in the preparation of the case report were the same.

\section{References}

1. Piga $M$, Serra A, Boi F, et al. Amiodarone-induced thyrotoxicosis. A review. Minerva Endocrinologica 2008; 33: 213-28.

2. Martino E, Bartalen L, Bogazzi F, Braverman LE. The effects of amiodarone on the thyroid. Endocrine Rev 2001; 22: 240-54.

3. Czarnywojtek A, Czepczynski R, Ruchala M, et al. Radioiodine therapy in patients with amiodarone-induced thyrotoxicosis (AIT). Neuroendocrinol Lett 2009; 30: 209-14.

4. Iskandar SB, Jordan RM, Peiris AN. Treating amiodaroneinducuced thyrotoxicosis with radioactive iodine. Tenn Med 2004; 97: 408-10.

5. Bogazzi F, Bartalena L, Martino E. Approach to the patient with amiodarone-induced thyrotoxicosis. J Clin Endocrinol Metab 2010; 95: 2529-35.

6. Siuda K, Kolesinska Z, Niedziela M. Amiodarone and thyroid function. Kardiol Pol 2011; 69: 493-8.
7. Piga M, Cocco MC, Serra A, Boi F, Loy M, Mariotti S. The usefulness of $99 \mathrm{~m}$ Tc-sestaMIBI thyroid scan in the differential diagnosis and menagement of amiodarone-induced thyrotoxicosis. Eur J Endocrinol 2008; 159: 423-9.

8. Tanda ML, Bogazzi F, Martino E, Bartelena L. Amiodaroneinduced thyrotoxicosis: something new to refine the initial diagnosis? Eur J Endocrinol 2008; 159: 359-61.

9. Sharma M, Aronow W, Patel L, Gandhi K, Desai H. Hyperthyroidism. Med Sci Monit 2011; 17: RA85-91. 